\title{
NGHIÊN CỨU XÂY DỤ̂NG MÔ HÌNH DỬ BÁO LŨ LƯU VỰC SÔNG HOÀNG LONG
}

\author{
Tống Ngọc Công ${ }^{1}$, Trần Ngọc Anh², Đặng Thanh Mai ${ }^{3}$
}

Tóm tắt: Bài báo trình bày các kết quả xây dụng mô hình dụ báo lũ cho hệ thống sông Hoàng Long dựa trên việc tích hợp các mô hình thủy văn, thủy lực và khai thác sản phẩm mura số trị tù mô hình hạn vìa Châu Âu. Các mô hình NAM (MIKE NAM), MIKE 11 được thiết lập, kiểm định và thư nghiệm với kết quả đạt được khá tốt cho phép sủ dụng bộ mô hình để tính toán dụ báo lũ cho luu vưc sông Hoàng Long trong điều kiện tác nghiệp. Mô hình dư báo được thử nghiệm với số liệu mưa sản phẩm mua số trị tù mô hình hạn vìa Châu Âu trong trận lũ tháng 7 năm 2018 cho kết quả dụ báo đáp ứng được các yêu cầu nghiệp vu.

Từ khóa: MIKE NAM, MIKE 11, Hoàng Long, Dư báo lũ.

Ban Biên tập nhận bài: 08/12/2018 Ngày phản biện xong: 15/02/2019 Ngày đăng bài: 25/02/2019

\section{Mở đầu}

Lưu vực sông Hoàng Long thuộc địa giới của 2 tỉnh Hòa Bình và Ninh Bình. Trong đó phần diện tích thuộc tỉnh Hoà Bình khoảng 1.000 km² (chiếm $66 \%$ diện tích toàn lưu vực), phần còn lại khoảng $515 \mathrm{~km}^{2}$ thuộc địa phận tỉnh Ninh Bình. Trong những năm gần đây, các loại thiên tai như lũ, ngập lụt trên lưu vực sông Hoàng Long tăng lên nhiều lần về tần số lẫn cường độ. Điển hình là vào năm 2017, mưa lớn tập trung trong thời gian ngắn đã gây ra lũ lớn, đặc biệt lớn trên lưu vực sông Hoàng Long. Dự báo lũ đóng vai trò rất quan trọng trong công tác phòng tránh, giảm nhẹ thiệt hại gây ra do lũ. Đặc biệt là lũ trên lưu vực sông Hoàng Long luôn có diễn biến phức tạp, khó lường đòi hỏi công tác dự báo ngày càng phải được chú trọng hơn.

Theo phân cấp trách nhiệm ban hành bản tin dự báo, cảnh báo Đài KTTV tỉnh Ninh Bình có trách nhiệm dự báo lũ trên sông Hoàng Long tại trạm Bến Đế và trạm Gián Khẩu. Xây dựng mô hình dự báo lũ trên sông Hoàng Long theo quan điểm đồng

'Đài Khí tượng Thủy văn tỉnh Hà Nam

${ }^{2}$ Khoa Khi tuoọng Thủy văn Hải duoong học,

Truòng Đại hoc Khoa Hoc Tụ nhiên

${ }^{3} V u$ quản lý dụ báo Khí tương Thủy văn, Tổng cuc Khi tương Thủy văn

Email: tongocong@gmail.com; thanhmaidang1973@gmail.com bộ và ứng dụng các mô hình hiện đại, đáp ứng các yêu cầu trong quá trình tác nghiệp cảnh báo, dự báo lũ là mục tiêu của nghiên cứu này.

\section{Số liệu và phương pháp nghiên cứu}

\subsection{Số liệu}

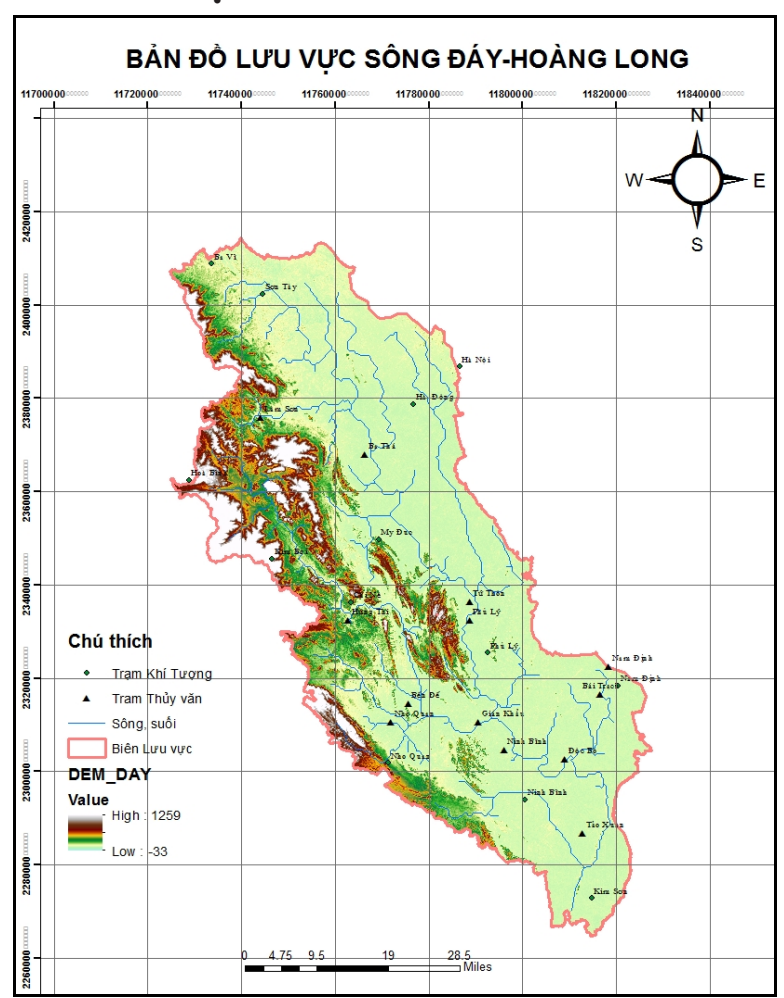

Hình 1. So đồ lưu vực hệ thống sông ĐáyHoàng Long

Các số liệu được sử dụng trong thiết lập và hiệu chỉnh/kiểm định mô hình gồm:

- Số liệu mưa (thời đoạn 6 giờ), số liệu bốc 
hơi của các trạm khí tượng trên lưu vực nghiên cứu.

- Số liệu dòng chảy tại Trạm Hưng Thi, Ba Thá đo khảo sát trong quá khứ.

- Số liệu mực nước mùa lũ của 4 trạm trong lưu vực trạm thủy Ba Thá, Phủ Lý, Hưng Thi, Gián Khẩu.

- Số liệu mặt cắt ngang, trắc dọc toàn tuyến hệ thống sông Đáy, Hoàng Long Các tài liệu có độ tin cậy cao và đã được các cơ quan sử dụng trong các dự án thuộc đồng bằng sông Hồng.

\subsection{Phương pháp nghiên cúu}

Dựa trên khả năng ứng dụng của các mô hình trong dự báo lũ, bộ mô hình Mike NAM, Mike11 kết hợp với các kết quả dự báo mưa tổ hợp (ECMWF) đã được lựa chọn trong xây dựng mô hình dự báo.

Để làm đầu vào cho mô hình dự báo lũ, kết quả dự báo mưa được lấy từ hệ thống dự báo tổ hợp ECMWF đang được vận hành nghiệp vụ tại trung tâm Dự báo KTTV quốc gia. Các kết quả dự báo mưa từ mô hình được phân tích, đánh giá so sánh với thực đo. Các kết quả này được hiệu chỉnh đảm bảo sát với thực tế trên cơ sở xây dựng tương quan với lượng mưa quan trắc thực tế và các phân tích đặc điểm mưa trên lưu vực.

Mô hình NAM tính toán dòng chảy từ mưa, là đầu vào cho các mô hình thủy lực và gia nhập khu giữa. Mô hình thủy lực Mike 11 được xây dựng để tính toán quá trình lũ các trạm dưới hạ lưu sử dụng các kết quả tính từ mô hình NAM. Các chỉ tiêu đánh giá chất lượng mô phỏng và kiểm định của mô hình gồm: Mức độ phù hợp giữa các kết quả tính toán và thực đo, chỉ số NASH, sai số đỉnh lũ và thời gian xuất hiện đỉnh lũ.

\subsubsection{Thiết lập mô hình MIKE NAM tính toán} dòng chảy tù mura

Lưu vực sông Đáy- Hoàng Long được chia thành 12 lưu vực bộ phận gồm gồm có các tiểu lưu vực BATHA, NHUE, CHAUGIANG, PHULY, NINHBINH, HUNGTHI, BENDE, GIANKHAU, LV1, LV2, LV3, DOCBO (Hình 2). Trong các tiểu lưu vực này chỉ có $\mathrm{BATHA}$ và HUNGTHI là các tiểu lưu vực có đo lưu lượng trong quá khứ, các tiểu lưu vực còn lại đều không có trạm đo lưu lượng.

Số liệu của 12 trạm mưa trong và lân cận lưu vực được sử dụng tính toán dòng chảy từ mưa theo phương pháp đa giác Thieson. Tối ưu bộ thông số và hiệu chỉnh mô hình sử dụng số liệu 2 trận lũ lớn nhất năm 2000 và 2017, kiểm định cho 2 trận lũ 2001 và 2010. Trạm thủy văn dùng để hiệu chỉnh/ kiểm định là Hưng Thi và Ba Thá.

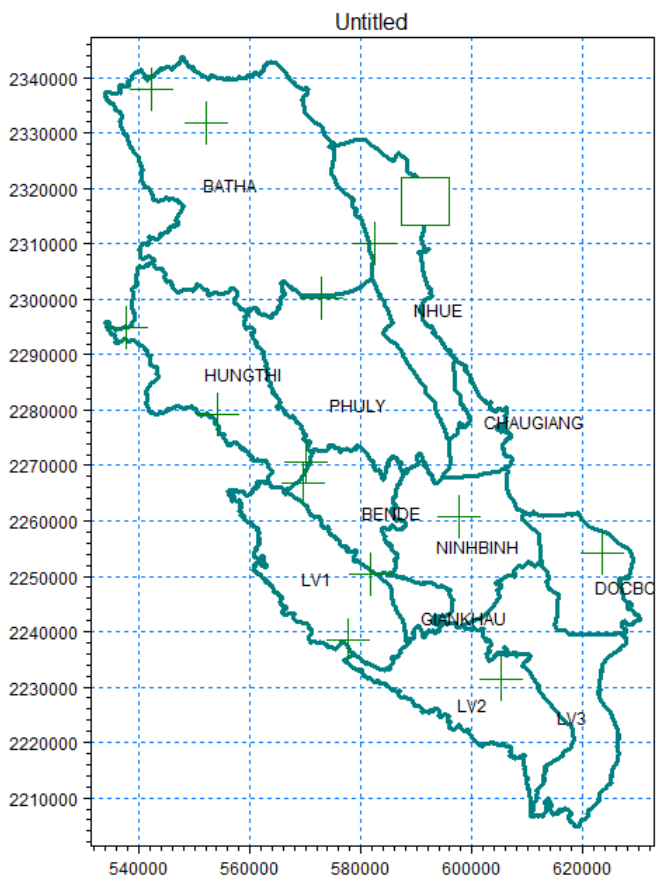

Hình 2. Các tiểu luu vục và vị trí các trạm đo mura trong mô hình NAM

\subsubsection{Thiết lập mô hình MIKE11}

Mạng lưới sông được mô phỏng bắt đầu từ trạm thủy văn Ba Thá, trạm Hưng Thi, cống Liên Mạc, cống Tắc Giang ra tới cửa biển. Trên cơ sở bản đồ DEM $30 \mathrm{mx} 30 \mathrm{~m}$ và bản đồ số mạng lưới sông đã xác định các sông chính trên lưu vực sông Đáy-Hoàng Long. Bản đồ số sau khi chuyển đổi về định dạng shape file với hệ tọa độ VN2000 được nhập vào môi trường MIKE 11. Sử dụng bộ biên tập mạng lưới sông thiết lập các mặt cắt ngang từ số liệu mặt cắt thu thập được. Sơ đồ thủy lực sông Đáy - Hoàng Long được trình bày trong hình 3 .

Biên trên gồm quá trình dòng chảy tại trạm khống chế phía thượng lưu là Ba Thá, Hưng Thi và cống Liên Mạc, cống Tắc Giang. Biên dưới là quá trình mực nước triều tại cửa Đáy với bước 


\section{BÀI BÁO KHOA HỌC}

thời gian là 01 giờ, được tính toán dựa trên mô hình dự báo triều toàn cầu, có sẵn trong bộ MIKE11. Biên khu giữa gồm lưu lượng của 10 tiểu lưu vực dọc theo dòng chính các sông được tính toán từ mô hình NAM. Trong các biên gia nhập khu giữa có lưu vực DOCBO bị ảnh hưởng bởi dòng chảy sông Hồng qua trạm thủy văn Nam Định, quá trình lưu lượng nhập lưu được lấy cố định bằng $600 \mathrm{~m}^{3} / \mathrm{s}$ là lưu lượng trung bình trong mùa lũ.

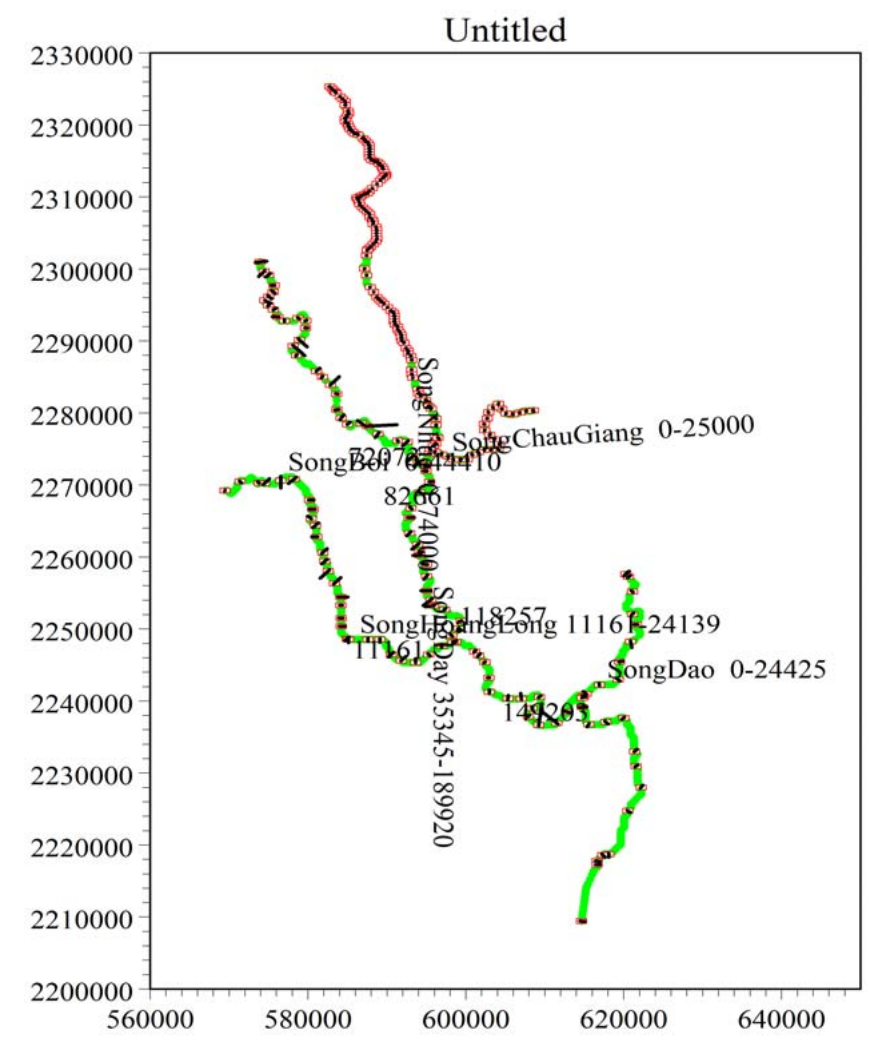

Hình 3. So đồ thủy lực sông Đáy - Hoàng Long trong MIKE 11

\section{Các kết quả và thảo luận}

\subsection{Hiệu chỉnh và kiểm định mô hình NAM}

Kết quả hiệu chỉnh mô hình NAM cho các trận lũ lưu vực sông Đáy-Hoàng Long khá tốt cả về đỉnh lũ, tổng lượng và quá trình. Đường quá trình mực nước lũ tính toán và thực đo tại trạm Hưng Thi và $\mathrm{Ba}$ Thá tương đối đồng dạng. Xu thế đường nước lên, đường nước xuống các trận lũ tính toán đều khá phù hợp với thực đo. Chênh lệch giữa đỉnh lũ tính toán và thực đo nhỏ dưới $5 \%$. Thời gian xuất hiện đỉnh lũ tính toán và đỉnh lũ thực đo ít có sự chênh lệch (từ 1 đến 3 giờ), riêng thời gian xuất hiện đỉnh lũ năm 2017 tại trạm Ba Thá xuất hiện sớm hơn so với thực đo. Nguyên nhân có thể do các trạm đo mưa trên lưu vực chưa phản ánh đầy đủ diễn biến mưa thực tế. Sai số tổng lượng tương đối nhỏ, chỉ số Nash đạt từ 0.838 đến 0.932 đều ở mức tốt. Tuy nhiên quá trình tính toán cho thấy có sự trễ pha ở vùng nước thấp và mô hình chưa mô phỏng được ảnh hưởng thủy triều. 

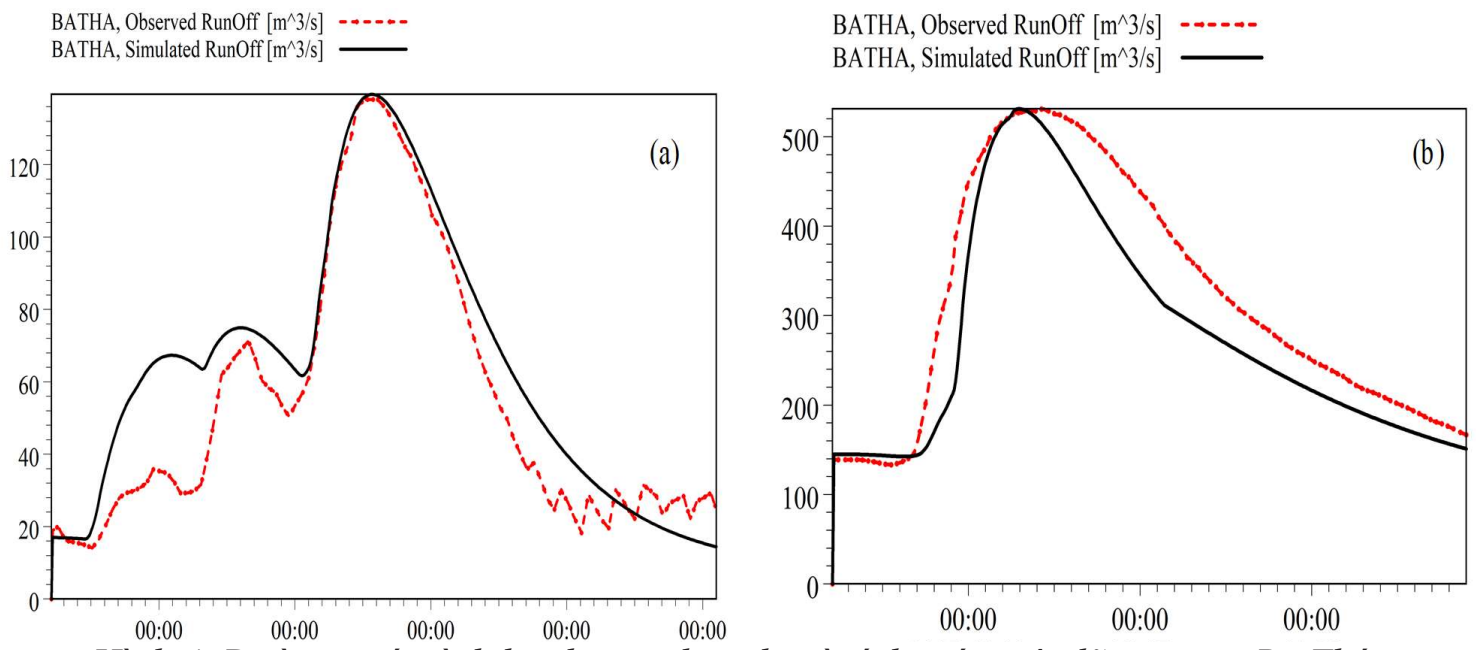

Hình 4. Đuòng quá trình lư lượng thực đo và tính toán trận lũ tại trạm Ba Thá năm 2000 (a) và 2017 (b)

HUNGTHI, Observed RunOff $\left[\mathrm{m}^{\wedge} 3 / \mathrm{s}\right]$ HUNGTHI, Simulated RunOff $\left[\mathrm{m}^{\wedge} 3 / \mathrm{s}\right]$

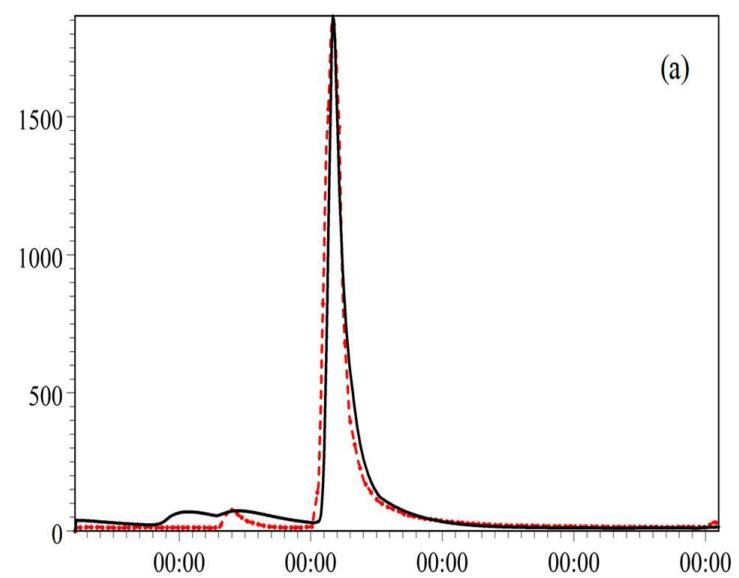

HUNGTHI, Observed RunOff $\left[\mathrm{m}^{\wedge} 3 / \mathrm{s}\right]$ HUNGTHI, Simulated RunOff $\left[\mathrm{m}^{\wedge} 3 / \mathrm{s}\right]$

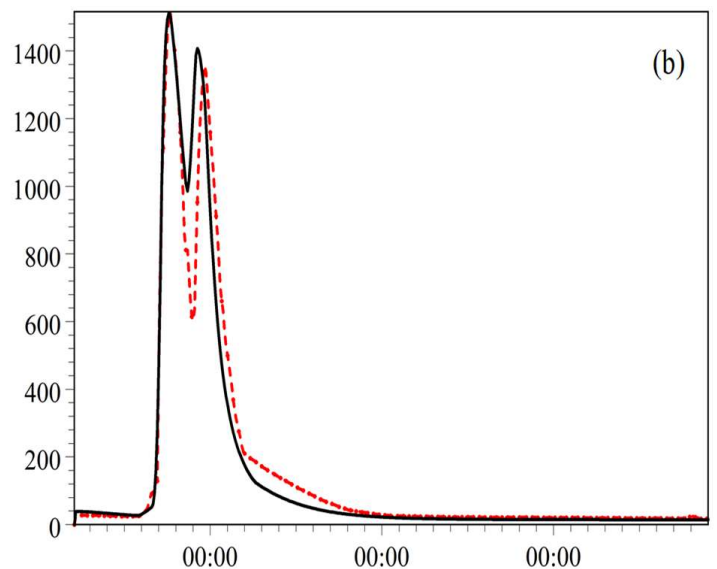

Hình 5. Đưòng quá trình lưu lượng thực đo và tính toán trận lũ tại trạm Hưng Thi năm 2000 (a) và 2017 (b)

Bảng 1. Chỉ tiêu đánh giá chất lượng hiệu chỉnh mô hình NAM

\begin{tabular}{|c|c|c|c|c|c|c|c|c|c|}
\hline Trạm & $\begin{array}{c}\text { Trận } \\
\text { lũ }\end{array}$ & Nash & $\begin{array}{l}\text { Qmax td } \\
\left(\mathrm{m}^{3} / \mathrm{s}\right)\end{array}$ & $\begin{array}{c}\text { Qmax } \\
\text { tt } \\
\left(\mathrm{m}^{3} / \mathrm{s}\right)\end{array}$ & $\begin{array}{l}\Delta \mathrm{Q} \\
(\%)\end{array}$ & $\begin{array}{c}\Delta \mathrm{t} \\
\text { (giờ) }\end{array}$ & $\begin{array}{l}\mathrm{W}_{\mathrm{td}} \\
\left(10^{6}\right. \\
\left.\mathrm{m}^{3}\right)\end{array}$ & $\begin{array}{l}\mathrm{W}_{\mathrm{tt}} \\
\left(10^{6}\right. \\
\left.\mathrm{m}^{3}\right)\end{array}$ & $\begin{array}{l}\Delta \mathrm{W} \\
\left(10^{6}\right. \\
\left.\mathrm{m}^{3}\right)\end{array}$ \\
\hline $\mathrm{Ba}$ & 2000 & 0,838 & 138 & 139 & 0,72 & 0 & 116 & 135 & 19 \\
\hline Thá & 2017 & 0,84 & 531 & 530 & 0,19 & 9 & 508 & 443 & 65 \\
\hline Hưng & 2000 & 0,906 & 1858 & 1861 & 0,16 & 0 & 184 & 190 & 6 \\
\hline Thi & 2017 & 0,932 & 1516 & 1512 & 0,26 & 1 & 251 & 239 & 12 \\
\hline
\end{tabular}

Quá trình kiểm định bộ thông số mô hình cho thấy đường quá trình lưu lượng tính toán với đường quá trình lưu lượng thực đo tại các trạm Ba Thá và Hưng Thi cho kết quả khá tốt về trị số đỉnh lũ và thời gian xuất hiện đỉnh, riêng thời gian xuât hiện trận lũ năm 2010 tại trạm Ba Thá sớm hơn so với thực đo 3-4 giờ. Xu thế quá trình lũ lên, lũ xuống giữa tính toán với thực đo đều phù hợp. Trong trận lũ kép năm 2001 tại Ba Thá đã có sự sai khác lớn ở đỉnh lũ nhỏ. Nguyên nhân 


\section{BÀI BÁO KHOA HỌC}

chủ yếu là do số liệu mưa thực đo chưa phản ánh đúng lượng mưa và phân bố mưa trên lưu vực.

Chỉ số Nash đạt được tương đối tốt từ 0.794 đến 0.852 , sai số tổng lượng nhỏ từ $10 \%$ đến
15\%. Bộ thông số tìm được sau quá trình hiệu chỉnh và kiểm định tương đối ổn định cho các vị trí kiểm định, có thể sử dụng để tính toán dòng chảy cho lưu vực trong dự báo tác nghiệp.

Bảng 2. Bộ thông số của mô hình NAM

\begin{tabular}{cccccccc}
\hline Lưu vực & $\mathrm{U}_{\max }$ & $\mathrm{L}_{\max }$ & $\mathrm{CQ}_{\mathrm{OF}}$ & $\mathrm{CK}_{\mathrm{IF}}$ & $\mathrm{CK}_{1,2}$ & $\mathrm{~T}_{\mathrm{OF}}$ & $\mathrm{T}_{\mathrm{IF}}$ \\
\hline BATHA & 10,2 & 52,5 & 0,879 & 636,4 & 85 & 0,0476 & 0,2065 \\
HUNGTHI & 10,1 & 81,5 & 0,878 & 203,4 & 25,4 & 0,0755 & 0,556 \\
\hline
\end{tabular}

BATHA, Observed RunOff $\left[\mathrm{m}^{\wedge} 3 / \mathrm{s}\right]$ BATHA, Simulated RunOff $\left[\mathrm{m}^{\wedge} 3 / \mathrm{s}\right]$

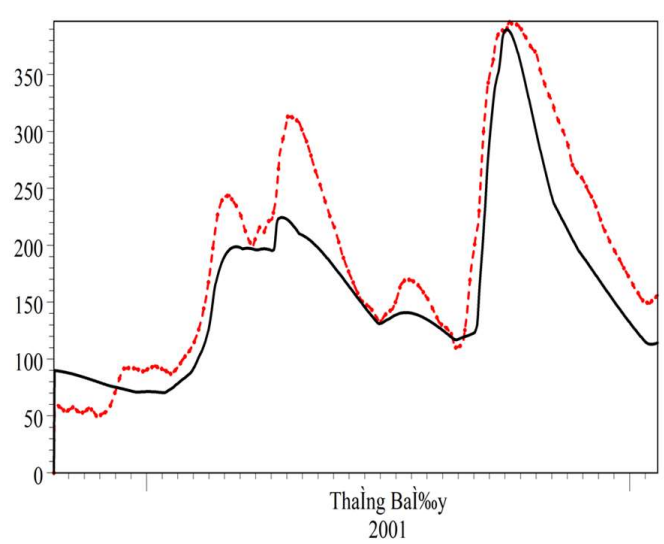

(a)
BATHA, Observed RunOff $\left[\mathrm{m}^{\wedge} 3 / \mathrm{s}\right]$ BATHA, Simulated RunOff [mค3/s] -

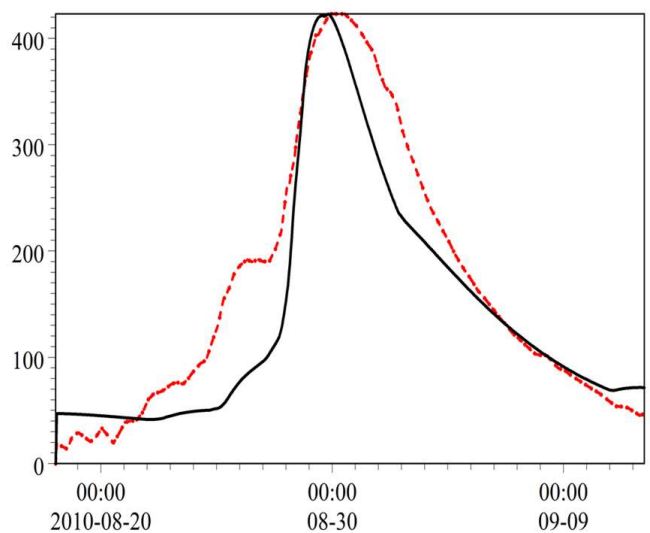

Hình 6. Đường quá trình lư lương thục đo và tính toán trận lũ tại trạm Ba Thá năm 2001 (a) và năm 2010 (b)
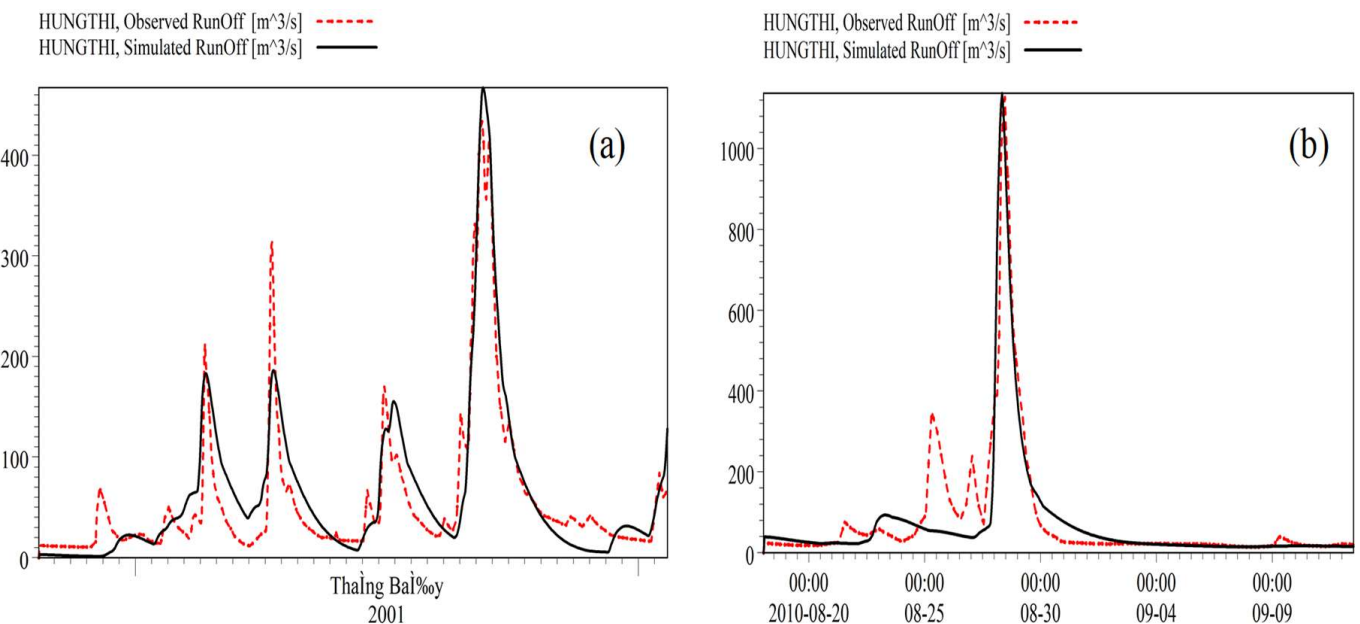

Hình 7. Đường quá trình lưu lượng thực đo và tính toán tại trạm Hưng Thi trận lũ năm 2001 (a) và năm 2010 (b) 
Bảng 3. Chỉ tiêu đánh giá chất lượng kiểm định mô hình NAM

\begin{tabular}{cccccccccc}
\hline Trạm & $\begin{array}{c}\text { Trận } \\
\text { lũ }\end{array}$ & Nash & $\begin{array}{c}\text { Qmax tđd } \\
\left(\mathrm{m}^{3} / \mathrm{s}\right)\end{array}$ & $\begin{array}{c}\text { Qmax } \\
\mathrm{tt} \\
\left(\mathrm{m}^{3} / \mathrm{s}\right)\end{array}$ & $\begin{array}{c}\Delta \mathrm{Q} \\
(\%)\end{array}$ & $\begin{array}{c}\Delta \mathrm{t} \\
\left(\mathrm{giờ}^{3}\right)\end{array}$ & $\begin{array}{c}\mathrm{W}_{\mathrm{td}} \\
\left(10^{6}\right. \\
\left.\mathrm{m}^{3}\right)\end{array}$ & $\begin{array}{c}\mathrm{W}_{\mathrm{tt}} \\
\left(10^{6}\right. \\
\left.\mathrm{m}^{3}\right)\end{array}$ & $\begin{array}{c}\Delta \mathrm{W} \\
\left(10^{6}\right. \\
\left.\mathrm{m}^{3}\right)\end{array}$ \\
\hline Ba & 2001 & 0.794 & 397 & 390 & 1.76 & 3 & 642 & 543 & 99 \\
Thá & 2010 & 0.852 & 423 & 419 & 0.95 & 4 & 366 & 311 & 55 \\
Hưng & 2001 & 0.839 & 434 & 467 & 7.6 & 1 & 192 & 210 & 18 \\
Thi & 2010 & 0.82 & 1124 & 1139 & 1.33 & 3 & 176 & 155 & 21 \\
\hline
\end{tabular}

3.2. Hiệu chỉnh và kiểm định mô hình thông qua quá trình hiệu chỉnh và kiểm định đối MIKE11

Mô hình MIKE-NAM được hiệu chỉnh trước tại các tiểu lưu vực, bộ thông số đối với các tiểu lưu vực được mượn từ bộ thông số thu được với lưu vực BATHA, HUNGTHI. Kết quả tính toán sẽ đưa vào mô hình MIKE11 qua các biên gia nhập khu giữa.
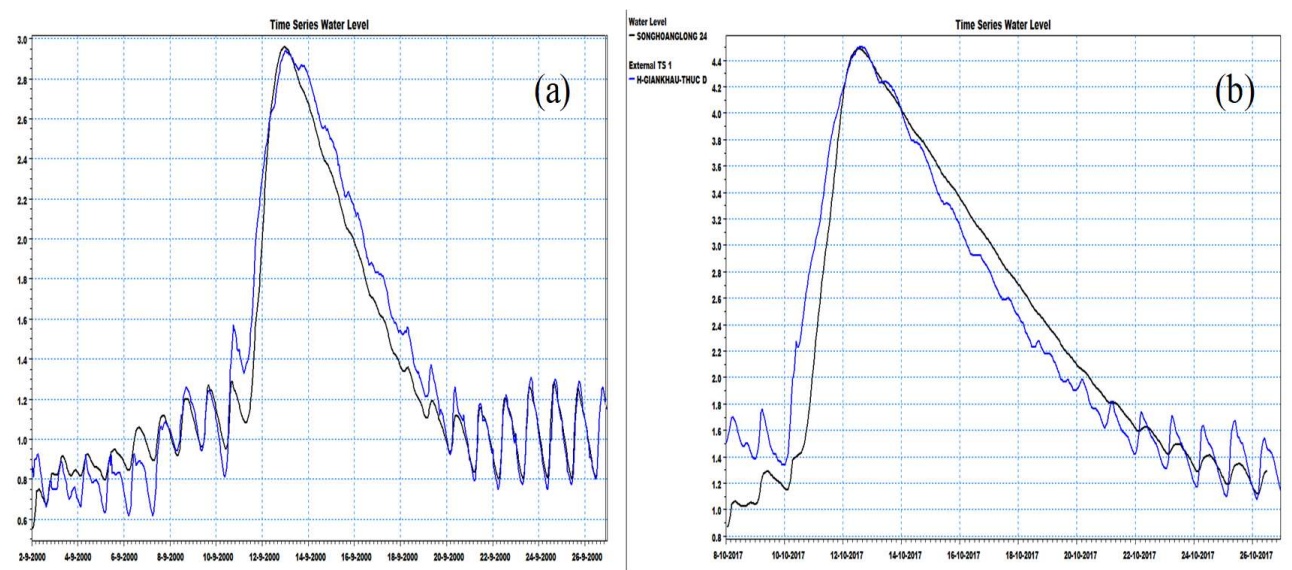

Hình 8. Đưòng quá trình mục nước trận lũ năm 2000 (a) và năm 2017 (b) tại trạm Gián Khẩu Bảng 4. Kết quả hiệu chỉnh mô hình MIKE11

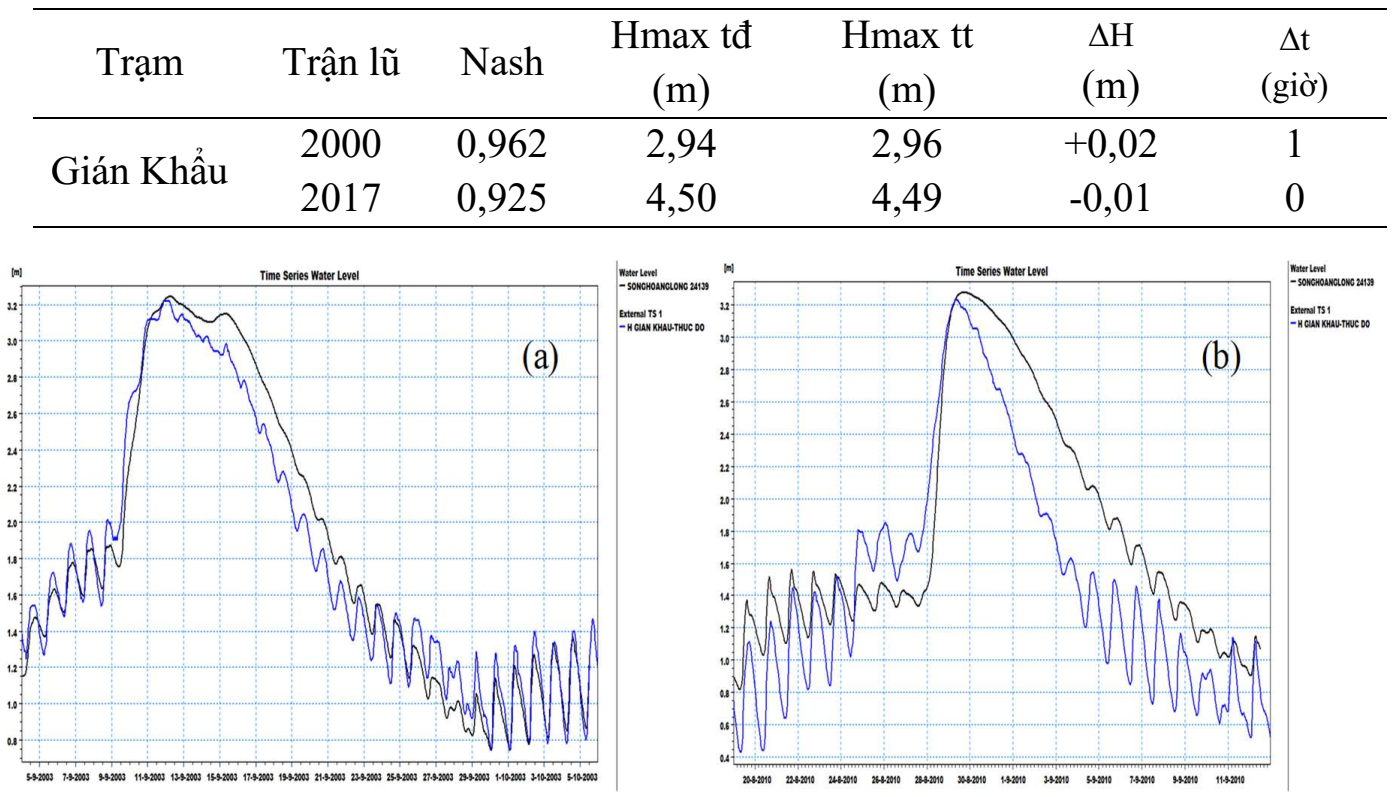

Hình 9. Đường quá trình mục nước trận lũ năm 2003 (a) và năm 2010 (b) tại trạm Gián Khẩu 
Bảng 5. Kết quả kiểm định mô hình MIKE 11

\begin{tabular}{ccccccc}
\hline Trạm & Trận lũ & Nash & $\begin{array}{c}\text { Hmax tđ̃ } \\
(\mathrm{m})\end{array}$ & $\begin{array}{c}\text { Hmax } \mathrm{tt} \\
(\mathrm{m})\end{array}$ & $\begin{array}{c}\Delta \mathrm{H} \\
(\mathrm{m})\end{array}$ & $\begin{array}{c}\Delta \mathrm{t} \\
(\text { giờ })\end{array}$ \\
\hline Gián Khẩu & 2003 & 0.943 & 3.22 & 3.25 & +0.03 & 0 \\
Gián Khẩu & 2010 & 0.774 & 3.23 & 3.29 & +0.06 & 4 \\
\hline
\end{tabular}

\subsection{Thử nghiệm bộ mô hình trong dụ báo nghiệp vụ}

Việc dự báo thử nghiệm nhằm mục tiêu đánh giá khả năng ứng dụng của mô hình trong điều kiện nghiệp vụ. Bộ mô hình được thử nghiệm cho trận lũ tháng 7 năm 2018 sử dụng quy trình dự báo thử nghiệm được trình bày trong hình 10 . Qua đó số liệu mưa dự báo trong 24 giờ của mô hình hạn vừa Châu Âu đã được sử dụng làm đầu vào cho mô hình NAM nhằm dự báo quá trình lưu lượng tại trạm $\mathrm{Ba}$ Thá và Hưng Thi và quá trình lưu lượng tại các tiểu lưu vực gia nhập khu giữa. Kết quả tính toán này cùng với kết quả dự tính biên triều được sử dụng làm đầu vào mô hình MIKE 11 dự báo quá trình lũ tại Gián Khẩu với thời gian dự kiến là 24 giờ. Kết quả dự báo thử nghiệm được đánh giá thông qua việc so sánh với sai số cho phép tại vị trí dự báo, sau đó tính phần trăm giữa số lần dự báo đúng với tổng số lần dự báo theo công thức $\mathrm{P}=(\mathrm{n} / \mathrm{N}) * 100 \%$ với $\mathrm{P}$ là mức bảo đảm dự báo $(\%), \mathrm{n}$ số lần dự báo đúng, $\mathrm{N}$ là tổng số lần dự báo. Theo quy định của Tổng cục Khí tượng thủy văn, sai số cho phép của trạm Gián Khẩu là $17 \mathrm{~cm}$ đối với thời gian dự kiến $12 \mathrm{~h} ; 27 \mathrm{~cm}$ đối với thời gian dự kiến $24 \mathrm{~h}$ và $40 \mathrm{~cm}$ đối với dự báo đỉnh lũ.

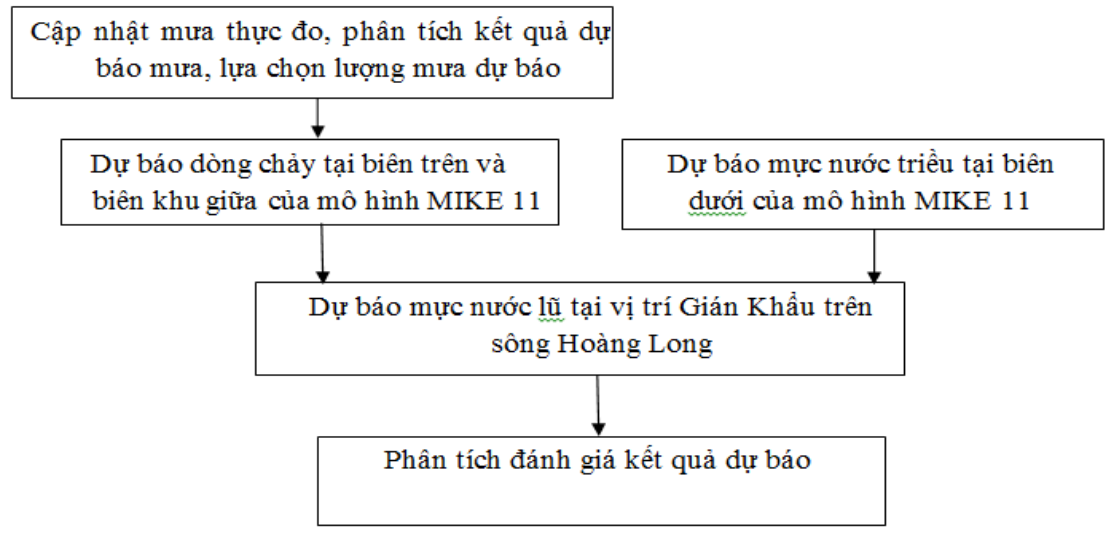

Hình 10. Quy trình dụ báo thư nghiệm

Kết quả thử nghiệm cho thấy các mô hình mô phỏng tốt quá trình thực tế tại các trạm phát báo. Quá trình nước lên và nước xuống khá phù hợp. Đường nước xuống có sai số lớn hơn đường nước lên. Kết quả dự báo đỉnh lũ tương đối tốt nhưng lệch phải (xuất hiện muộn khoảng 3-6 giờ). Dự báo đỉnh lũ kép cho kết quả tốt, mực nước dự báo và thời gian xuất hiện nằm trong sai số cho phép. Kết quả dự báo thử nghiệm tại các vị trí dự báo với thời gian dự kiến 12 giờ đạt $70 \%, 24$ giờ đạt $78 \%$, cơ bản đáp ứng được yêu cầu về chất lượng dự báo. Các mô hình là một công cụ hiệu quả giúp dự báo viên trong việc phân tích và dự báo lũ, từng bước nâng cao chất lượng dự báo lũ cho lưu vực sông Hoàng Long.

\section{Bảng 6. Kết quả dụ báo thủ nghiệm}

\begin{tabular}{cccccc}
\hline Sông & Trạm & $\begin{array}{c}\text { Thời gian } \\
\text { dự kiến }\end{array}$ & $\begin{array}{c}\text { Tổng số lần } \\
\text { dự báo }\end{array}$ & $\begin{array}{c}\text { Số lần } \\
\text { dự báo đúng }\end{array}$ & $\mathrm{P} \mathrm{( \% )}$ \\
\hline Hoàng & Gián & $12 \mathrm{~h}$ & 40 & 28 & 70 \\
Long & Khẩu & $24 \mathrm{~h}$ & 40 & 31 & 78 \\
\hline
\end{tabular}




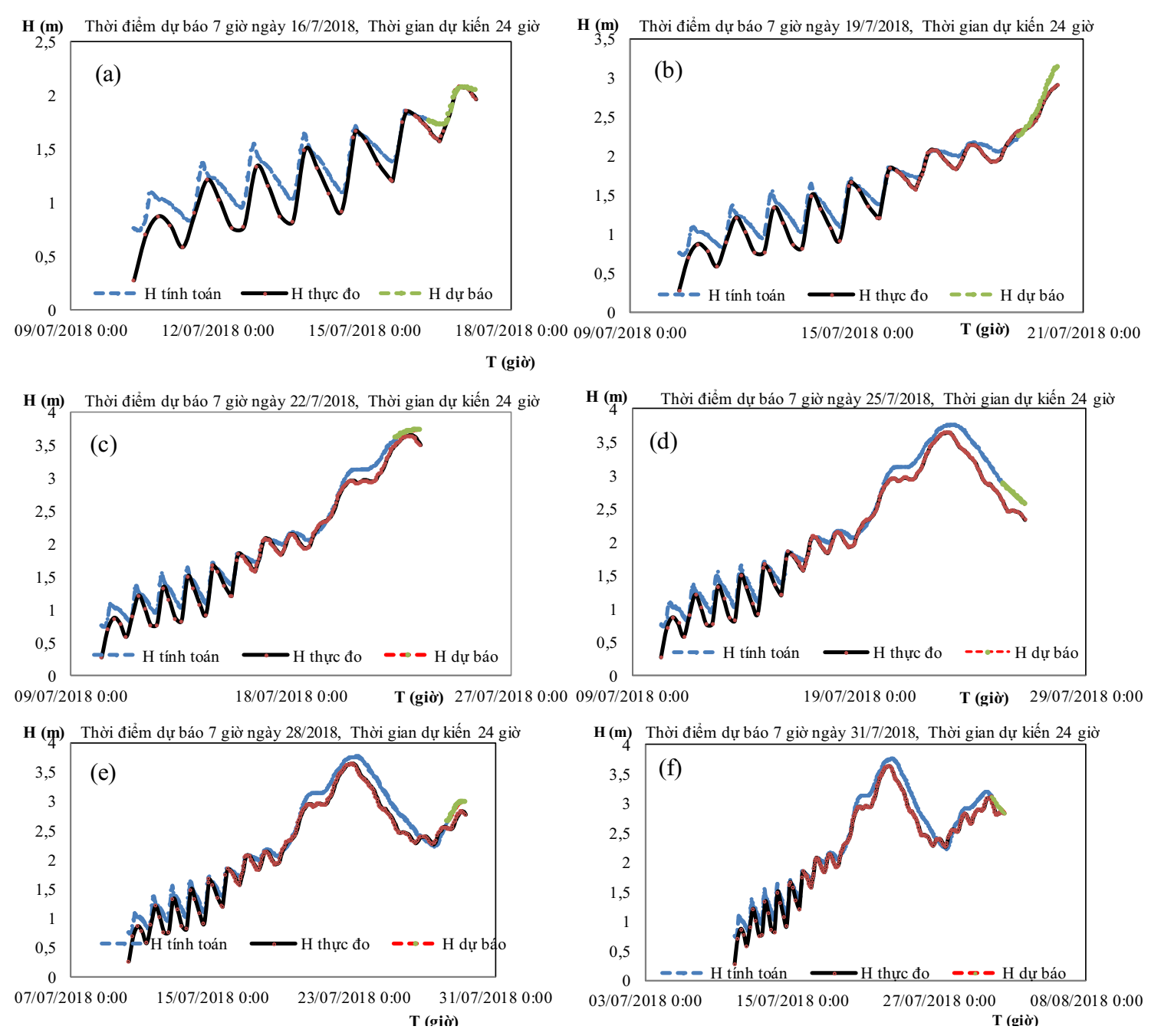

Hình 11. Quá trình mực nước dụ báo và thực đo tại Gián Khẩu

Bảng 7. Kết quả Đánh giá dụ báo đỉnh lũ

\begin{tabular}{ccccccc}
\hline Sông & Trạm & $\begin{array}{c}\text { Hmax tđ } \\
(\mathrm{m})\end{array}$ & $\begin{array}{c}\operatorname{Hmax} \\
\mathrm{db}(\mathrm{m})\end{array}$ & $\begin{array}{c}\Delta \mathrm{H} \\
(\mathrm{m})\end{array}$ & $\begin{array}{c}\Delta \mathrm{t} \\
(\text { giờ })\end{array}$ & $\begin{array}{c}\text { Đánh } \\
\text { giá }\end{array}$ \\
\hline $\begin{array}{c}\text { Hoàng } \\
\text { Long }\end{array}$ & $\begin{array}{c}\text { Gián } \\
\text { Khẩu }\end{array}$ & 3.64 & 3.78 & +0.14 & -6 & Đúng \\
\hline
\end{tabular}

\section{Kết luận}

Đối với hệ thống sông Hoàng Long, nghiên cứu tích hợp các mô hình trong tính toán và dự báo lũ đảm bảo hiệu quả và đạt độ tin cậy có vai trò quan trọng trong công tác dự báo giảm nhẹ thiên tai lũ, lụt. Trong nghiên cứu này, mô hình NAM được thiết lập tối ưu, kiểm nghiệm nhằm mô phỏng, dự báo dòng chảy từ mưa làm đầu vào cho mô hình thủy lực. Mô hình MIKE 11 được thiết lập tối ưu, kiểm nghiệm để mô phỏng dòng chảy lũ vùng hạ lưu hệ thống sông. Bộ mô hình đã được thử nghiệm trong điều kiện tác nghiệp cho trận lũ tháng 7/2018 sử dụng số liệu mưa từ mô hình hạn vừa châu Âu. Kết quả kiểm nghiệp và thử nghiệm cho thấy bộ mô hình đáp ứng được các yêu cầu dự báo và cho phép dự báo tác nghiệp dòng chảy lũ cho hệ thống sông Hoàng Long khi sử dụng số liệu các dự báo mưa số trị hoặc từ các nguồn dự báo mưa khác.

Đây là một công cụ hỗ trợ tốt cho các dự báo 


\title{
BÀI BÁO KHOA HỌC
}

viên trong việc đưa ra kết quả dự báo nhanh chóng, tuy nhiên, tính chính xác còn phụ thuộc nhiều vào các kết quả dự báo định lượng mưa và hiệu chỉnh bộ thông số, các yếu tố này cần được cập nhật và hiệu chỉnh thường xuyên trong quá trình tác nghiệp.

Lời cảm ơn: Kết quả nghiên cứu là một phần nội dung luận văn của học viên Tống Ngọc Công. Nhóm nghiên cứu xin chân thành cảm on sự hỗ trợ của đề tài BĐKH.24/16-20 trong việc thực hiện và công bố nghiên cứu này.

\section{Tài liệu tham khảo}

1. Bùi Văn Chanh và Trần Ngọc Anh (2016), Tích hợp bộ mô hình dụ báo thuỷ văn lưu vực sông Trà Khúc, Tạp chí Khoa học Đại học Quốc gia Hà Nội.

2. Đặng Đình Đức (2012), Nghiên cưu xây dựng bản đồ tính dễ bị tổn thương cho lưu vưc sông Nhuệ Đáy trên địa bàn thành phố Hà Nội, Luận văn Thạc sỹ, Trường Đại học Khoa học Tự nhiên, Đại học Quốc gia Hà Nội.

3. Nguyễn Ý Như (2011), Nghiên cứu tác động của biến đổi khi hậu đến cực trị dòng chảy trên lưu vực sông Nhuệ Đáy thuốc địa bàn thành phố Hà Nội. Luận văn Thạc sỹ, Trường Đại học Khoa học Tự nhiên, Đại học Quốc gia Hà Nội.

4. Đặng Thị Lan Phương (2012), Nghiên cưu ứng dụng mô hình MIKE tùng bước hoàn thiện công nghệ dư báo lũ sông Hồng - Thái bình. Luận văn Thạc sĩ khoa học, ĐH Khoa học Tự nhiên ĐH Quốc gia Hà Nội.

5. Lại Thị Thanh(2014), Nghiên cưu quy hoạchphòng chống lũ sông Hoàng Long trong điều kiện không xây dưng hồ chứa nước Hung Thi, Luận văn Thạc sỹ, Trường Đại học Thủy lợi.

6. Trần Thục (2011), Xây dưng công nghệ tính toán dụ báo lũ lớn hệ thống sông Hồng - Thái Bìn, Đề tài cấp Bộ.

7. DHI (2007), MIKE ZERO Software Package, Rainfall-Runoff Parametters.

\section{APPLICATION MODELS TO FLOOD FORECASTING IN HOANG LONG RIVER BASIN}

\author{
Tong Ngoc Cong ${ }^{1}$, Tran Ngọ Anh ${ }^{2}$, Dang Thanh $\mathrm{Mai}^{3}$ \\ ${ }^{1} \mathrm{Ha}$ Nam province Hydrometeorological centre \\ ${ }^{2}$ Faculty of Hydro-meteorology \& Oceanography \\ ${ }^{3}$ Department of Meteorological and Hydrological Forecasting Management
}

\begin{abstract}
The paper presents the results of application the models for flood forecasting in the Hoang Long river basin which based on the integration of hydrological and hydrolic models and rainfall forecasting data from the European medium model. NAM and Mike 11 models were established, calibrated and verified which give good results for use in flood forecasting for the Hoang Long river basin in operational conditions. The forecast models is tested with rainfall forecasting data in the flood events in July 2018. The testing results show that the technology meets the requirements in operational conditions.
\end{abstract}

Keyword: MIKE NAM, MIKE 11, Hoang Long, Flood forecasting. 